Article

\title{
Cultural Memories and Sense of Place in Historic Urban Landscapes: The Case of Masrah Al Salam, the Demolished Theatre Context in Alexandria, Egypt
}

\author{
Fatmaelzahraa Hussein ${ }^{1,2, * \mathbb{D}}$, John Stephens ${ }^{1}(\mathbb{D})$ and Reena Tiwari ${ }^{1}$ \\ 1 School of Design and Built Environment, Curtin University, Perth, WA 6845, Australia; \\ J.Stephens@curtin.edu.au (J.S.); r.tiwari@curtin.edu.au (R.T.) \\ 2 Department of Architectural Engineering, High Institute of Engineering and Technology, \\ El Behira 22699, Egypt \\ * Correspondence: f.hussein@postgrad.curtin.edu.au; Tel.: +61-469606078
}

Received: 6 July 2020; Accepted: 6 August 2020; Published: 7 August 2020

\begin{abstract}
Historic urban landscapes (HULs) are composed of layers of history and memories that are embedded in physical monuments, buildings, and memorials. Physical built fabric stores both personal and cultural memory through long association with communities. Rapid changes due to demolition and redevelopment change the nature of these places and, in turn, affect these memory storages. This paper investigates whether historical city inhabitants consider cultural memories important when managing their HULs. It further explores the effectiveness of cultural memory in creating a sense of place and enhancing the quality of life for inhabitants. The context of the demolished theatre 'Masrah Al Salam' in Alexandria, Egypt, was studied after city inhabitants angrily protested the theatre's removal, indicating a strong community attachment to this lost place. A qualitative methodological approach to this study was applied by conducting on-site, semi-structured, face-to-face interviews supplemented by comments gathered from the Facebook group 'Alexandria's Spirit'. The QSR NVivo12 program was used as a qualitative tool for data management, analysis, and mapping intangible elements contributing to an assembly of cultural memories of this place. The study demonstrated the importance of cultural memory associated with urban elements such as iconic heritage buildings that create a sense of place and enhance the identity of our urban environments.
\end{abstract}

Keywords: cultural memories; historic urban landscapes; place attachment; quality of life; sense of place

\section{Introduction}

This paper investigates whether historical city inhabitants consider cultural memories important when managing their historic urban landscapes (HULs). In addition, it explores how cultural memory plays an effective role in creating a sense of place for enhancing each inhabitant's quality of life.

Historic cities are a kind of palimpsest for the imprint of historical events and are a reflection of their identities [1]. Urban settings and landscapes consist of layers of history and memories that are apparent in physical urban elements such as significant buildings, monuments, and public and governmental spaces [2].

However, the expansion of cities—as a result of increasing populations-requires rapid physical changes that destroy familiar urban features and elements, creating unfamiliar environments and causing gentrification and the destruction of memory and place identity [3]. As a result, the United Nations Educational, Scientific and Cultural Organisation (UNESCO, 2011) introduced the concept of HUL to help protect historic urban settings [4]. HULs have been usefully defined as 'the complex 
layering of cultural and natural values and attributes that contribute to identity and sense of place' as a new understanding of historic urban settings [5]. This has also created a new approach to urban heritage, as it aims to integrate urban conservation with urban planning strategies by focusing on the social and cultural values that people attach to urban areas as well as the built environments [4]. Taylor argued that 'memories' are an important social value. 'Landscape is a cultural construct, a mirror of our memories and myths encoded with meanings that can be read and interpreted' [6].

In its simplest definition, memory is 'the mental capacity or faculty of retaining and reviving impressions, or of recalling or recognising previous experiences' [7]. Memories could be individual or collective. For many people who can remember and share a memory, this pushes it to go beyond an individual's perspective to enter the collective one [8].

Collective memory is the act of remembering events that are associated with objects, places, and experiences by individuals in a social framework or between groups experiencing these events [3]. Collective memory is counted as a repository of culture, a view that sometimes leads to the terms 'collective memory' and 'cultural memory' being conflated [9].

Cultural memory has been studied in a wide range of interdisciplinary literature, such as psychology, sociology, geography, and built environments. Maurice Halbwachs and Pierre Nora are considered to be the founders of the recent cultural memory studies, particularly in the discipline of built environments [2]. Maurice Halbwachs saw that a 'collective memory' was an effect of a complex social framework of shared individual memories [10]. Pierre Nora was more concerned with spatial cultural memory (collective memory) studies, and he explained that certain sites can capture emotions and embody national memories [11]. For Fine (2005), collective memory is the way in which 'history enters into social life through by which individuals, organisations, and states interpret, recall and commemorate the past'. While variously defined by many individuals over the course of the twentieth century and since, it remains an interpretation 'on the individual or collective level: as social psychology or as collective representation' [12].

Inspired by these theorists, architectural theorist Aldo Rossi introduced the term 'urban memory' as a new idea of understanding cultural memory in the city. Urban memory has focused on the concentration of memory in the landscape of the city and the urban sites as a 'palimpsest' to store memories that can be read in significant buildings, monuments, museums, and public and governmental spaces [3]. This concept was then modified by Boyer in 1994 in her book The City of Collective Memory to link cultural memory and urban transformation. In the book, she argued that the city fabric contains the earlier forms and images of the city memory traces. She discussed how the city images are developed and how they directly relate to everyday urban life and economic and political concerns influencing cultural memory [2]. In addition, she explained that the city is an architectural collective expression that carries traces of memories, primary architectural shapes, city plans, and public monuments [13]. This research also touches on Halas's (2008) search for a meaning for collective memory and its symbols within a globalising culture and how a community's collective memory can become a 'social problem' in the erasure of memory or its alteration-ostensibly the erasure or alteration of local identity. In a sense, the site chosen for this study has become victim to a global notion of progress and is a cultural battleground, that through local processes of collective memory and experience, becomes a 'glocal' 'place of conflict about the symbolic representation of ongoing changes' [14]. Similarly, Al- Ghanim et al. (2017) pointed out the effect of globalisation on local cultures, noting that in Qatar, the replacement of traditional marketplaces with western style malls has had effects in changing customary cultural habits. The study showed there were 'culturally troubling' effects and uncovered an ambivalent attitude to the changes to culture and daily rituals-from acceptance amongst younger interviewees to a recognition of the consequences of change and threat to cultural identity amongst older members of families [15].

All these scholars established that reproducing and recalling cultural memory is place-specific, and landscapes as places are vessels for family stories and community memories [16]. So, the link is formed between cultural memories, everyday activities, and landscapes, forming a clear sense of the past and reinforcing the attachment to places [17]. 
Place attachment is defined by scholars as 'the bonds that people develop with places' $[18,19]$ expressed through the interchangeable roles of emotions, knowledge and beliefs, and behaviour and actions [20]. This includes the three components of place attachment: affective, cognitive, and practice [21,22]. The affective component is reflected in emotional attachments to places, whereas the cognitive component concerns thoughts, knowledge, and beliefs related to places. Furthermore, practice refers to the behaviour and activities that occur within spatial contexts [21].

The value of place attachment is in sustaining the attraction and meaning of places by avoiding the loss of their characteristics that are meaningful and familiar to their users [23]. Attachment towards a place is developed when the place is significant and well-identified by users; it fulfils their functional needs and supports their behavioural goals better than any known alternative [24].

This points to another important concept when dealing with people's bonds with places-'place identity'. This is defined as 'the set of features that guarantee the place's distinctiveness and continuity in time' [25]. Place identity is considered as the contribution of the features of a place to one's self-conception [26]. These are composed of physical forms and elements, as well as activities and meanings [27] that are associated with an individual's internal psychosocial processes to generate personal perception [28]. That buildings and public places are invested with cultural memories linked to identity is the subject of Bevan's book The Destruction of Memory: Architecture at War. Bevan argued that war brings with it the wanton destruction of places as an attempt to eradicate memory and identity—ostensibly to demoralise a people and enforce forgetting. Bevan recognised that the violent destruction of buildings may also happen in the name of 'progress' but added that ultimately-whether from benign or malign intentions-the result is similar "to lose all that is familiar-the destruction on one's environment—can mean a disorientating exile from the memories they have invoked" [29].

There is no agreement in the literature about how place attachment and place identity are related. Some scholars considered place identity a component of place attachment [30]. Others have recognised place identity and place attachment as two interchangeable concepts [25]. Others, as well as this research, treated place identity and place attachment as two different, although related, concepts-combining in the formation of the multidimensional phenomena of 'sense of place' [31]. Relph (1976) explained the difference between place attachment and place identity as the way a person can feel attached to a place for different reasons (e.g., the emotional bonds that people develop with places), while forming the identity of the place varies according to the agreed individual or group image of the place [32].

Sense of place as a multidimensional concept was studied and theorised by a number of research fields, including sociology, geography, and environmental psychology. It was defined by Fritze Steele (1981) as 'the particular experience of a person in a particular setting (feeling stimulated, exited, joyous, and so forth)' [33]. David Hummon (1992) took Steel's definition further by adding that 'sense of place is inevitably dual in nature, involving both an interpretive perspective on the environment and an emotional reaction to the environment' [34]. According to Eisenhauer's study (2000), sense of place has three variables: place interactions of families or friends, their traditions, and the memories associated with the people of the place $[35,36]$.

Therefore, sense of place plays an important role in HUL contexts, focusing on the effects of how people 'feel' and 'appreciate' a place by inhabiting and interacting within the place [37]. Sense of place is founded on three main components: functional/physical components, activities, and meanings/symbols [6]. So, memories and local identities can provide an accurate reflection of how people enjoy and are attached to their urban environments [38].

As in the above context, having places that make people feel comfortable and appreciated is linked to a sense of well-being and quality of life. The World Health Organisation (WHO) defined quality of life as 'an individual's perception of their position in life in the context of the culture and value systems in which they live and in relation to their goals, expectations, standards and concerns. It is a broad ranging concept affected in a complex way by the person's physical health, psychological state, personal beliefs, social relationships and their relationship to salient features of their environment' [39]. Datel and Dingemans (1984) defined sense of place as the complex bundle of meanings, symbols, 
and qualities of a person or a group associated with a particular locality or region [40]. These definitions support Jackson's (1994) belief that sense of place has the ability to create a sense of well-being and quality of life [41].

Growing populations and global urban transformations have impacted the identity of cities and sense of place [3]. In addition, current governmental practices tend to underestimate studies concerning cultural memories and sense of place, which have been shown to be important for maintaining the image and identity of historical cities [13]. However, we cannot transform all city streets into museums, but we at least need to protect urban symbols that recall memories and events for people. Sense of place and well-being are achieved when our space experience is familiar and continues to meet our expectations [42].

Alexandria is the second largest city in Egypt and is an ancient historical city experiencing major ongoing urban management plans to cope with growing population needs and urban development. Masrah Al Salam (Al Salam Theatre) was one of the most important features within the city urban fabric and waterfront. It was a theatre that witnessed many famous plays and shows that have been preserved and remembered in the memory of Alexandrians. The theatre was closed and neglected for five years and then removed-it is now in the process of being replaced by a recreational project. This presented a huge physical and cultural urban transformation that has affected city memories, images, sense of place, and residents' well-being. This study is a part of integrated case-based research project aiming at studying the "role of cultural memory in achieving psychosocial well-being in HULs" within the context of Alexandria, Egypt. In our previous research, we reviewed the existing relations between cultural memory, HULs and well-being in order to elaborate their important, yet neglected, role in achieving quality of life [43]. In another study, we utilised the case of Orabi Square, as one of the HULs in Alexandria (Egypt), in order to explore the site's historical and new conditions and place experience. In the aforementioned study, we were able to demonstrate that cultural memory is an active catalyst for emotional attachment to place, and is an important factor informing sense of place for better place experience [44].

Building on our previous research, in this study we aim to focus on exploring the level of importance given to cultural memory by inhabitants of the area surrounding Al Salam Theatre site in Alexandria (Egypt). In addition, this research explores the role of cultural memory in the construction of place attachment, place identity and sense of place and their contribution for enhancing the inhabitants' well-being and quality of life.

\section{Materials and Methods}

\subsection{Study Setting}

Alexandria is one of the most celebrated and important cities in Egypt, the Mediterranean Basin, and the world (Figure 1). It has a total area of 2679 square kilometres and a population of 5.2 million (in 2018), and it has the most important and oldest of the Egyptian harbours [45]. The city was chosen to conduct this research because of its historical importance and the ongoing urban changes to overcome the rapid urban growth that stressed the city's HULs, affecting their stored emotions and threatening the city's image survival.

The selected study site of the demolished Masrah Al Salam (El Salam Theatre) context has recently been subjected to a tangible urban setting transformation as follows:

The Masrah Al Salam (Al Salam Theatre) 'Mustafa Kamel' district in eastern Alexandria was opened in 1954 to become one of the most unique features of the city waterfront (Figure 2). It was famous for its elliptical form and for its shell structure system. The unique theatre was designed by the architect Samir Rabee (1936-2016) to be one of the few buildings in Egypt with this structural system and form [47]. It was also one of the oldest theatres located in eastern Alexandria. For over 62 years, it was known for presenting Egypt's most famous plays, and it holds irreplaceable memories for many generations that grew up watching their favourite actors in live performances [48]. This site was 
chosen for our study on the basis of the wave of frustration that erupted among many Alexandrians as a result of the theatre's demolition, pointing to its importance to the community. This Mediterranean front theatre had been closed for about five years without any maintenance, increasing the rate of deterioration. Despite the long-term closure, the theatre was still held in high esteem, and people expressed their deep sadness for its loss and how it affected their perceived (well-known) cognitive city image.

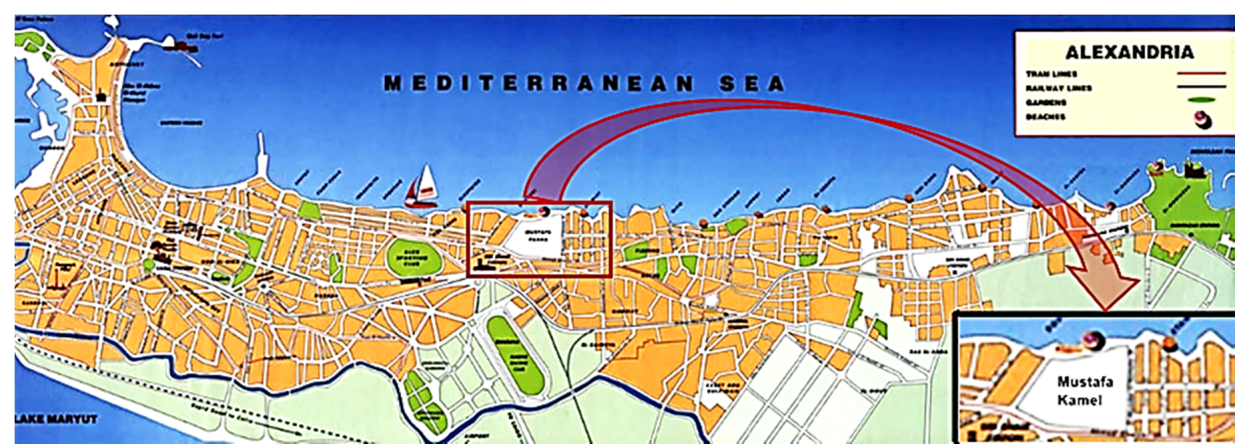

(a)

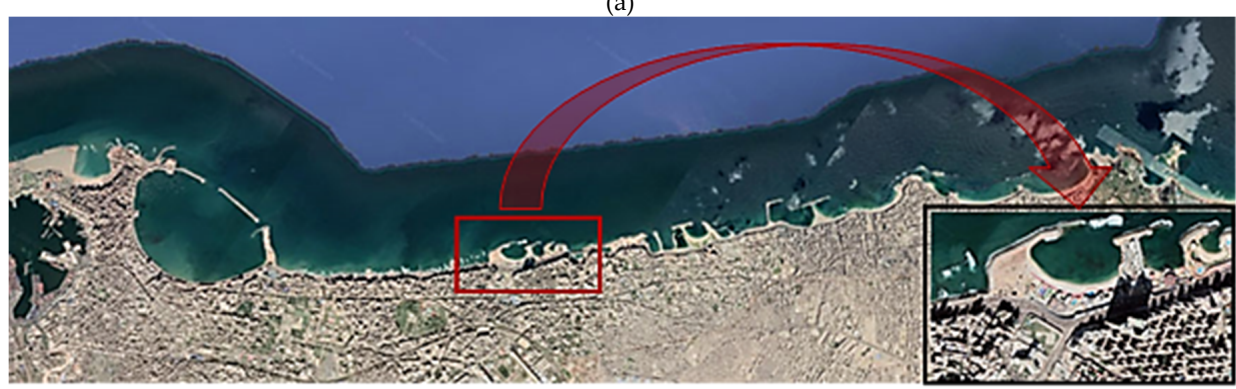

(b)

Figure 1. (a) Alexandria's map with 'Mustafa Kamel' district enlarged. Source: [46]. (b) Alexandria's Google Earth map with 'Mustafa Kamel' district enlarged. Source: Google Earth.

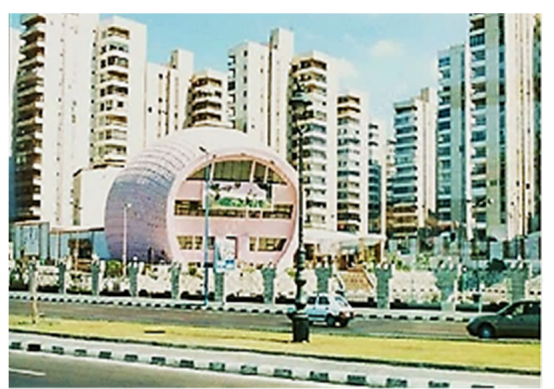

(a)

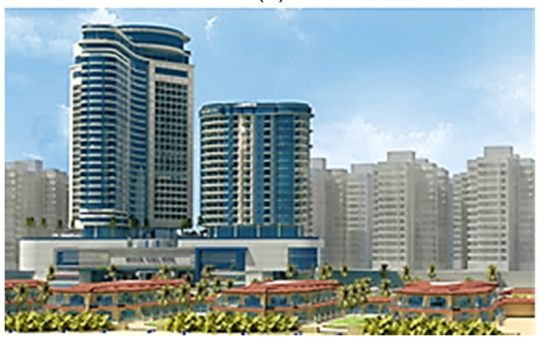

(c)

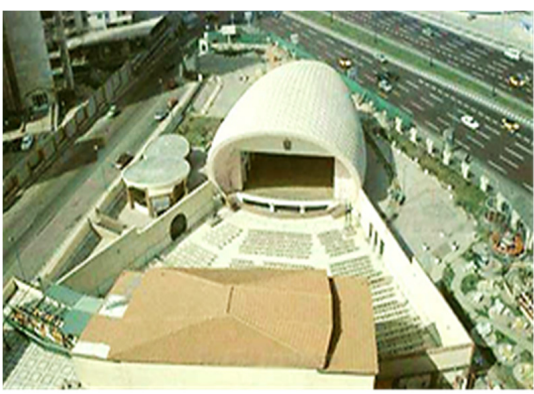

(b)

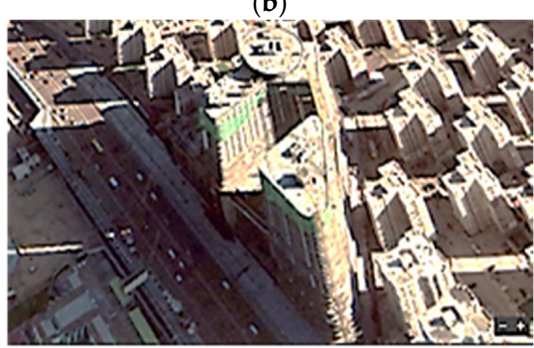

(d)

Figure 2. (a) Al Salam Theatre in its original context. Source: [49]. (b) Al Salam Theatre site plan view. Source: [49]. (c) A 3D view of the new hotel project that replaced the theatre. Source: [50]. (d) A Google Earth view showing the new unfinished hotel project replacing the theatre site plan. Source: Google Earth. 


\subsection{Data Collection and Analysis}

This research used the qualitative approach in studying and exploring the dimensions of the research problem. The research data were collected in two phases; the on-desk library research phase followed by the on-site research phase.

The library research was conducted to build the theoretical framework of the research through literature review for the research of HUL, cultural memory, place attachment, place identity, sense of place, and quality of life and to determine the cross relations between these main concepts to produce the research conceptual skeleton as well as the interview questions to be used in the second phase.

Throughout the second phase, face-to-face on-site interviews of the users in the context of the demolished Masrah Al Salam (Al Salam Theatre) were conducted. The interview questions were designed, and pilot tested on two interviewees to check questions for clarity and to identify the time requirements. The pilot interviews resulted in minor modifications to the wording of the questions, and the final revised semi-structured interview consisted of 20 questions covering the research's conceptual themes [44].

The sample size included 12 interviews that were guided by a previous qualitative study by Janice M. Morse (1994), who argued that researchers should have at least five participants when the aim of the qualitative research is to understand the nature of an experience [51].

The interviews targeted two main clusters: static users (people with constant engagement with the place) and mobile users (people with no daily engagement with the place) as six participants for each cluster, and they were selected by simple random sampling (the respondents were approached randomly in the street). Table 1 briefly shows the participants' characteristics. Each on-site interview lasted 30 to 45 minutes, and all of the participants answered all of the 20 semi-structured questions. All of the interviews were conducted during the time frame of July through August 2018, and all of the participants were asked if their interviews could be recorded and transcribed. Interviewees were given informed consent forms and guaranteed that they would remain anonymous.

Table 1. The demolished Masrah Al Salam context interview participants' characteristics. Source: F. Hussein.

\begin{tabular}{cccc}
\hline Age & Women & Men & Total (No.) \\
\hline $19-34$ & 2 & 3 & 5 \\
$35-49$ & 3 & 2 & 5 \\
$50-65$ & 0 & 2 & 2 \\
\hline
\end{tabular}

Guided by a number of previous studies, such as those by Gregory (2015) and Van der Hoeven (2018), the data collection second phase also included the use of social media in research [52,53]. This was done through creating a public Facebook group named 'Alexandria's Spirit' in June 2018 to collect people's opinions and narratives concerning their HULs without the stress that accompanies the traditional face-to-face interviewing methods [54]. It also gave participants a more creative medium to reflect their ideas and thoughts through posting comics and diagrams. According to the Human Research Ethics Committee of Curtin University, Australia (Permit No. HRE2018-0698), participants in the Facebook group were informed ahead that the collected data will be used for research purpose and that the status of the group will be public-hence, participants' comments and their data will be publicly available and accessible on the world wide web (the Facebook group is accessible at: https://www.facebook.com/groups/1801504963488546/).

To date, the number of the Facebook group members has reached 90 participants. The page hosted photos for the old and new situations of the site, leaving the participants with an open commentary field for anyone to post and exchange opinions. The data collected from 'Alexandria's Spirit' group included 42 comments, specifically for the demolished Masrah Al Salam (El Salam Theatre) context, that were all copied into document files for further processing. 
The research used the qualitative triangulation method for the data analysis by combining the use of on-site observations and interviews to extract a deeper view [55]. For the gathered Facebook data, the qualitative content analysis of the accumulated comments was used to elaborate on the participants' opinions, memories, and feelings of sense of place [56].

For data management and coding, a project was created using QSR NVivo 12 analytical software. The main research concepts were then broken down to nodes and sub-nodes (as required by this software) to create the research themes' tree node structure (Figure 3). All of the interview participants' statements and the Facebook group participants' comments were directly collected and copied into document files to be coded within the nodes and the sub-nodes to identify the cross-dimensional relations between the main concepts and extract the results.

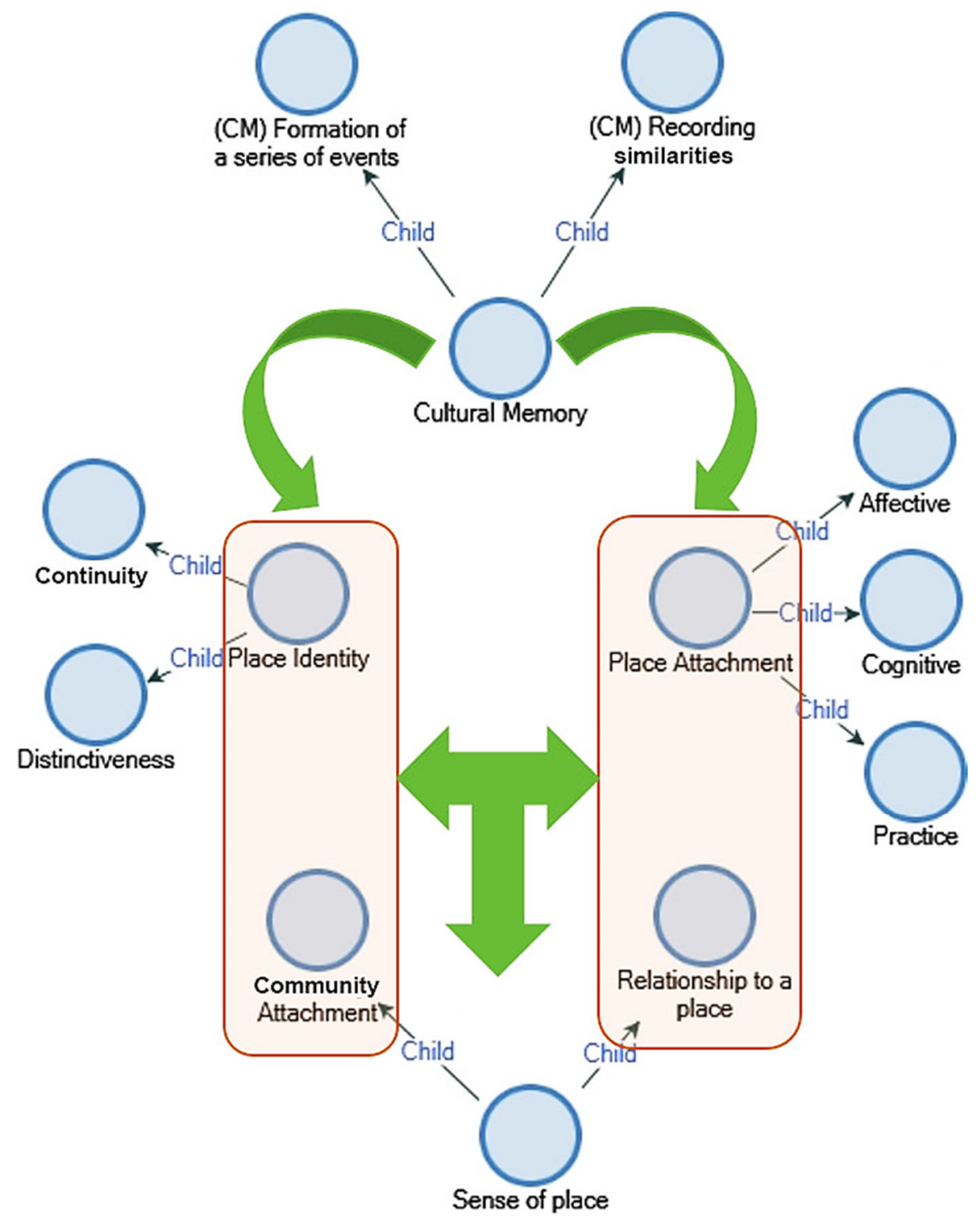

Figure 3. Diagram showing the main research themes and relations used through the coding process in the form of tree node-'nodes and sub-nodes'. Extracted from Nvivo12 program and modified by researchers. Source: F. Hussein.

\section{Results}

On-site interviewees and Facebook contributors emphasised the importance of a sense of place in HULs working as a palimpsest in remembering events in the context of the demolished Masrah Al Salam (Al Salam Theatre). Participants' data further reveal the relations between HUL, cultural 
memory, place attachment, place identity, sense of place, and quality of life. All of these relations were extracted through the qualitative content analysis for the interview, including collected manuscripts and the Facebook comments with relation to the proposed conceptual framework of the research. The following findings were reached, as described below.

\subsection{Cultural Memories Stored in the Place (Formation of Events and Recording Similarities)}

The participants emphasised that the urban site of the theatre was a context for their lived events as they remembered their good memories and experiences at the theatre, such as attending different plays and shows with their families and friends. In addition, most of the interviewees (8 out of 12) mentioned that the site amplified the feeling of summer holidays-this appeared in the NVivo extracted word query (Figure 4). They mentioned that they used to rent summer houses in the theatre's urban area to enjoy the beautiful sea view of Alexandria.

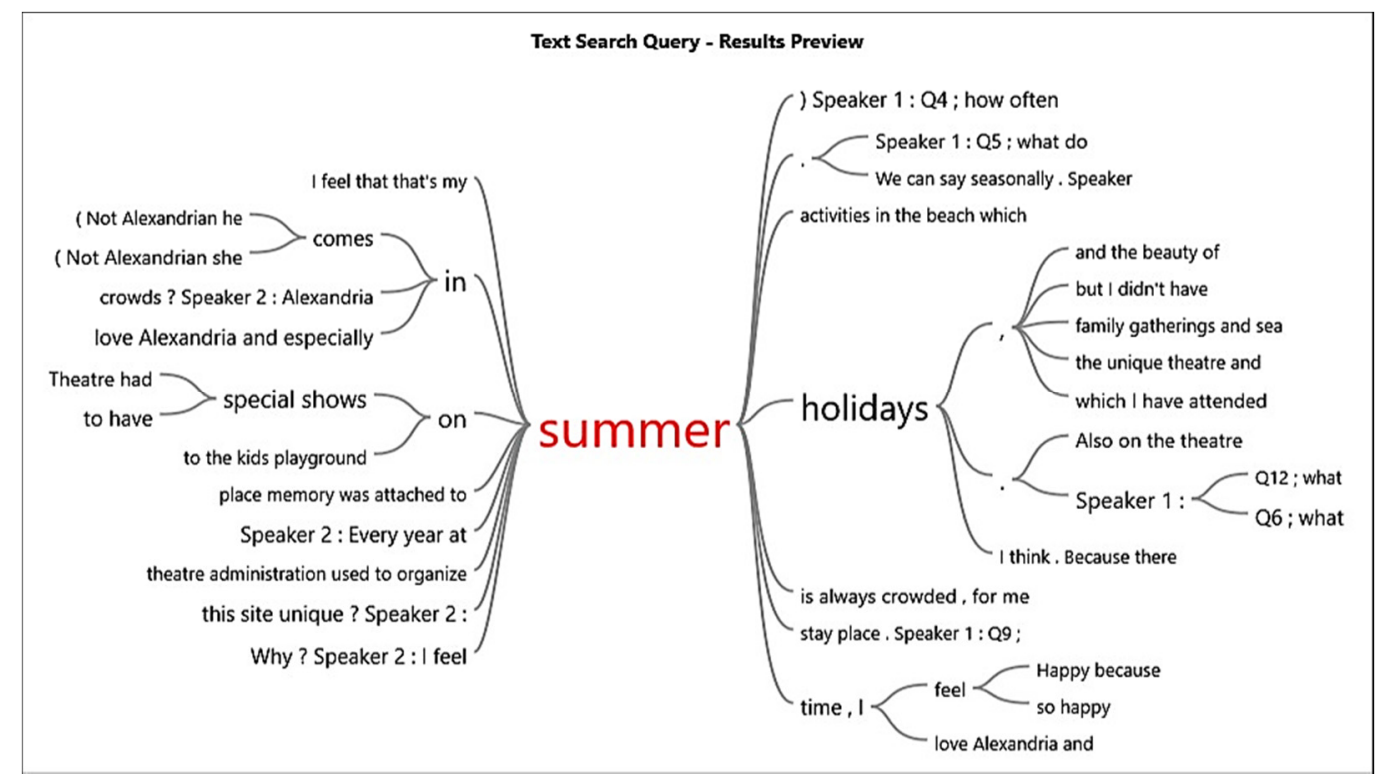

Figure 4. Word tree query, showing the frequency of mentioning summer by the participants, extracted through Nvivo12. Source: F. Hussein.

All Facebook group participants expressed the value of their memories that were stored in the site and lost by the theatre's demolition and major changes of its urban context.

'Removing the theatre is an unforgivable crime! I entered this theatre once when I was a child to attend a puppet show. However, every time I passed by the theatre I used to smile just because I remember that great time and how I was so happy that day. Also, because I used to feel that the kids who were playing in the theatre's front garden are enjoying the same feelings that I enjoyed when I was young, I think what happened is a destruction for the site's memory and symbolism'-Heba Moo'nis (sample of analysed Facebook comments)

All interviewees mentioned that there was no specific story or legend connected to this site, except the recently evolved anger that accompanied the theatre's removal and the dramatic change in the whole context (Figure 5) design to a new design that they hate and refuse to accept.

'There is no specific story that was connected to the theatre except its old repetition of exceptional summer plays that people used to attend long times ago. While, now there is the debate between Alexandrians around removing the theatre and how people were angry about that. This affects my experience by feeling angry every time I pass and remember how we lost the theatre despite the peoples refusing and I feel sorry for that'-23-year-old female interviewee (sample of analysed answers). 


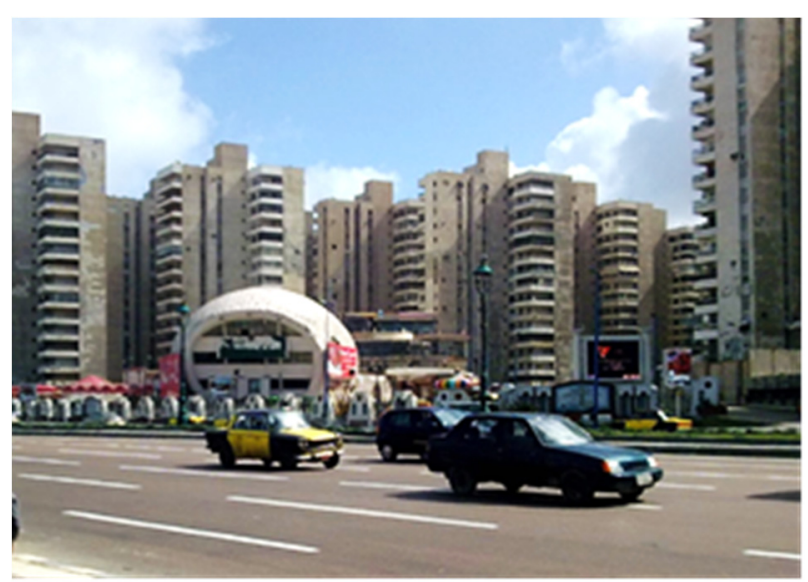

(a)

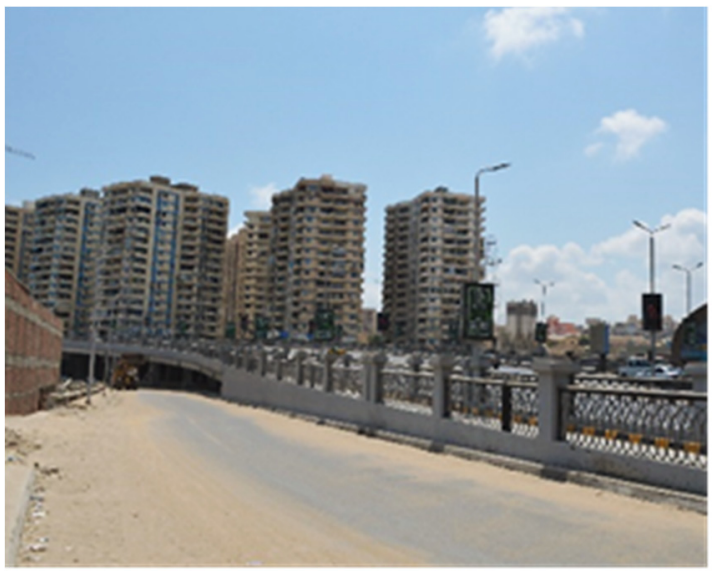

(b)

Figure 5. (a) The photo showing the Al Salam Theatre and its context before demolition. Source: [57]. (b) A recent photo from the same angle of view after removing the theatre, adding the traffic bridge, and changing the whole context. Source: F. Hussein.

\subsection{Place Attachment (Practice, Cognitive, and Affective)}

All of the interviewees showed attachment to the site as a result of practice-previously discussed as referring to the behaviour and activities that occur within spatial contexts-as some of the users were living in the area and others saw it as a mark to locate themselves within the city and determine their position; it was acting as a landmark for them.

Most of the interviewees (7 out of 12) and all of the Facebook comments were cognitively attached to this HUL as a result of their stored memories and knowledge related to the site, as they mentioned that this site is a symbol of the great theatre plays and a reminder of enjoyable family times.

'I'm so bonded to this place, first because a live here. Second because I used to come and play in the theatre's removed playground so it was a gathering place for me and my friends. Also it's like a guide for me, it's in the middle of Alexandria's promenade, so even if you are not coming specifically for the site you will pass by it any way it was a landmark'-43-year-old female interviewee (sample of analysed answers).

The participants showed different opinions and emotions towards the site after redevelopment. Among the younger generations, two interviewees expressed feelings of happiness and enjoying being in the place, even after the new changes. However, a larger number (8 out of 12) expressed anger and sadness due to the loss of the old place, resulting in a loss of affective bonds.

\subsection{Site Identity (Continuity and Distinctiveness)}

Participants mentioned their feelings that the place created confidence in the continuity of their city's well-known waterfront features. But this sentiment has been replaced by feelings of uncertainty and loss after the on-going changes.

All participants mentioned that the area has always been famous and known for the presence of the unique theatre's architectural form-now replaced with typical urban materials that they think has been replicated across the city and that lacks demand. Participants also mentioned that the site was unique in its setting and that the sea view is now blocked by the new traffic bridge. Another change was the removal of a small square with an artefact reflecting Alexandria's Greek-Roman historical background that was substituted with a new artefact that all users say is ugly and lacks any symbolism (Figure 6). They consider this a waste of the area's potential and distinctiveness, rejecting this change in the site's typology. This was reflected in the Facebook comments, as people started to create and post comics to express their opinions about the new artefact, comparing it to an old famous children's show puppet (Figure 7). 
'I' $m$ already uncomfortable about losing the eye contact with the sea view, due to the new changes and the traffic bridge. Because having a sea view was part of my experience here and that leaves me feeling that this is not the same place that I used to come to before and enjoy'-27-year-old female interviewee (sample of analysed answers)

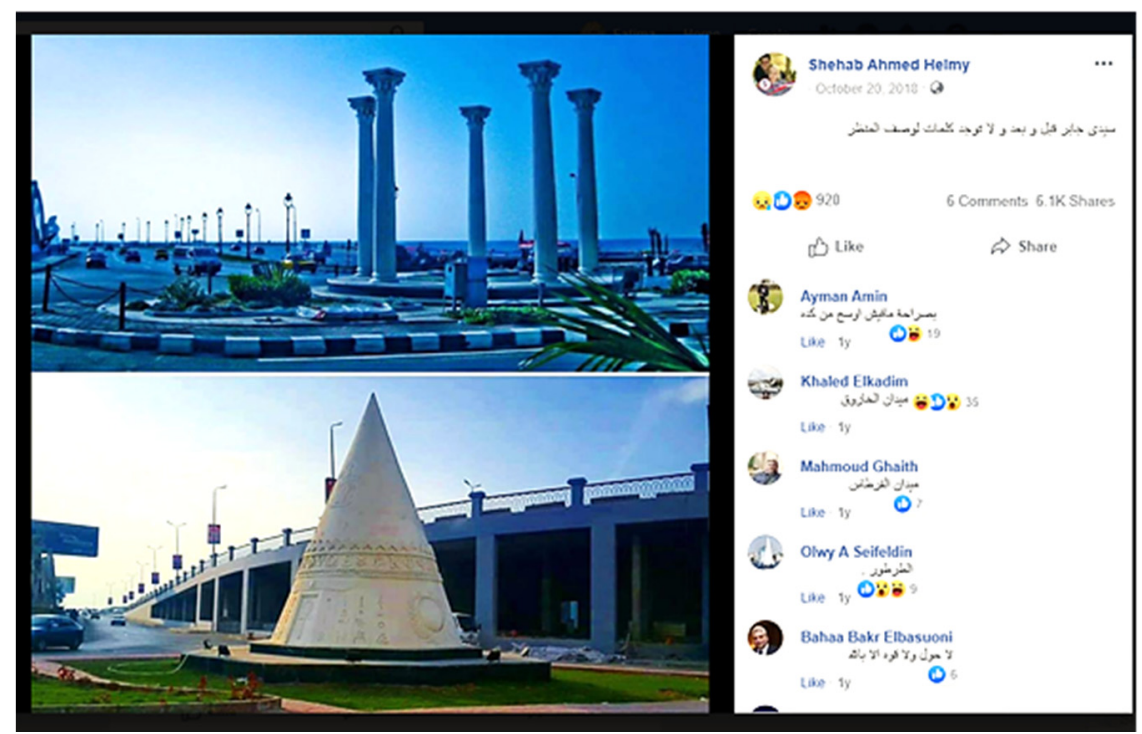

Figure 6. A screenshot of one of the Facebook group comments about these two photographs with the same angle of view. The main comment by Shehab Ahmed Helmy says, 'The area before and after, and no words can describe this scene'. Source: F. Hussein.

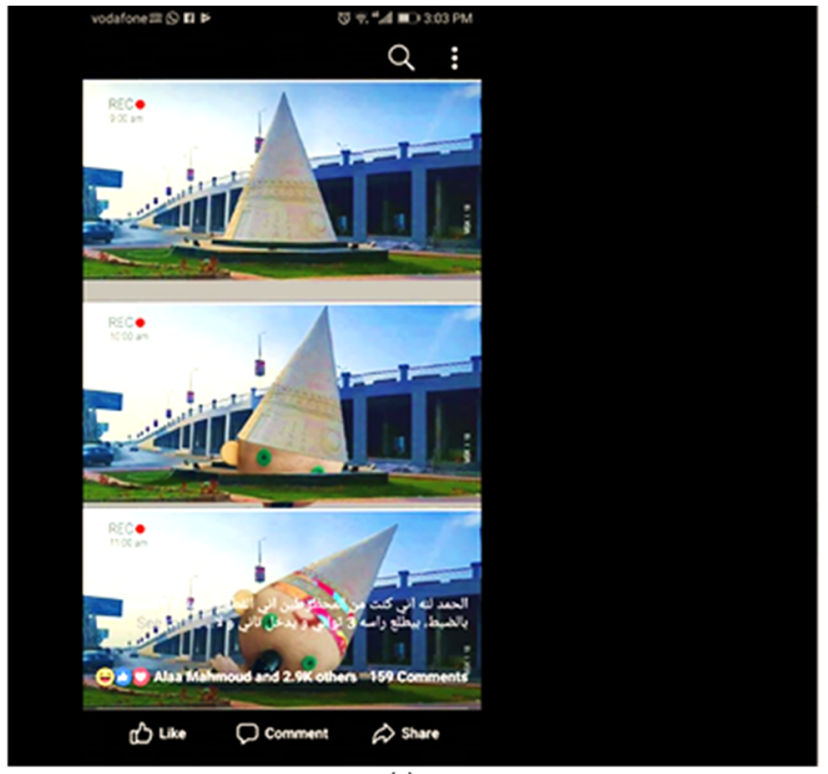

(a)

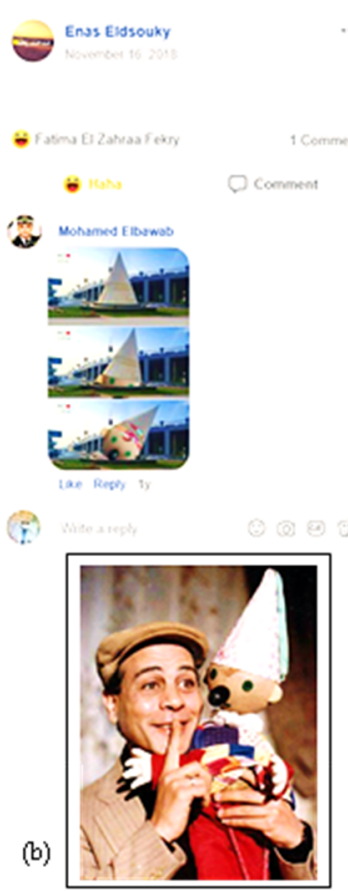

Figure 7. (a) A screenshot of one of the Facebook group comments about the new artefact. The main comment by Enas Eldsouky says, 'Thanks God, I was from the luckiest people who succeeded to spot boa'loz while his three seconds appearing in the early morning'. Source: F. Hussein. (b) Photo of boa'loz the puppet in a famous children's show in the early 1990s. Source: [58]. 


\subsection{Sense of Place (Relationship to the Place and Community Attachment)}

(a) Relationship to a place; biographical, spiritual, ideological, narrative, commodified, and dependent bonds.

All participants expressed that they used to have a relationship with the site, which has been affected badly due to the theatre's removal, changing their site experience and sense of place.

'I' $m$ very sad because of losing the theatre. Also, uncomfortable about the new buildings preventing the sea view and causing a big traffic jam. The area has lost its old spirit and it is totally changed now. I would prefer that the theatre has been kept with off course conservation and renovation, and adding the shopping and dining services this would have been a very nice entertaining complex'-53-year-old male interviewee (sample of analysed answers)

Interviewees primarily expressed three types of place relationships when talking about the site. The first is biographical bonds by static users, as all of them mentioned that they feel bonded to the place because they have been raised there and lived there. The second is ideological bonds across all of the static users and most of the mobile (five out of six participants) users, who mentioned that they used to see the theatre's site as a touchstone and landmark to locate themselves in the city to which they were also bonded by the activities that they practiced at the site. The third is narrative bonds across all of the interviewees, as they all mentioned that they were attached to stories about the great plays and shows that used to take place at the theatre, as well as the famous actors whose performances they saw and enjoyed during the summer.

(b) Community attachment; rootedness, place alienation, relativity, and 'placelessness' —defined by Relph (1976) as the process of a space losing its distinct identity and becoming commonplace [28].

All participants agreed that they used to be confident when interacting in the site and they were completely rooted to the context. However, after the latest changes, they are experiencing placelessness because of the drastic changes to the area that they do not accept. In addition, they said that to enjoy the site now, people have to be wealthy enough to use the new services such as the restaurants and the hotel. All participants mentioned that the area became so crowded, especially at the end of the bridge, creating unpleasant noise and the stress of foot traffic congestion.

'The area became so crowded, I don't like crowds specially the traffic ones, it's so annoying and time consuming. Also crowds make you feel that the place is small even if it's big and that is uncomfortable and pushes people to react more angry and tensioned. Now you can't enjoy having a walk viewing the open sea view, you have to go to a restaurant or a café to enjoy that, you have to be rich!'-50-year-old male interviewee (sample of analysed answers)

Almost all of the interviewees (10 out of 12) —and all of the Facebook comments-mentioned that they are unsatisfied with the new situation, and they mentioned how the whole area lost its old appeal, and now they cannot enjoy being there or taking a walk like before. They also mentioned that they were sad that they did not have the power to stop such an unwanted project.

'I feel sad and ashamed for the idea of existing and living during this period of time witnessing this tragic deterioration and after all I couldn't stop it or change it'. -Kareem Bahgat Al-Maghrabi (sample of analysed Facebook comments)

\section{Discussion}

This research aimed to investigate whether historical city inhabitants consider cultural memories important for managing their HULs. Additionally, it explored how cultural memory plays an effective role in creating a sense of place for enhancing the inhabitants' quality of life. First, the study indicated that people appreciate the importance of their individual and cultural memories in shaping their HULs. They also appreciate the importance of the site's stored memories and history in creating its sense of place through place attachment and identity and how this sense of place affects their site experience and quality of life. 
The findings indicate that factors such as the formation of events and recording similarities are important for reproducing and recalling cultural memories. The theatre landscape was inhabited by memories of summer holidays and was important to the participants. This finding supports the definition of cultural memory by Ardakani and Oloonabadi (2011) to be 'a series of events remembered by a group of people who share it and involve themselves in shaping it' [8]. Additionally, it complies with Assmann's and Kansteiner illustration that "cultural memory comprises that body of reusable texts, images, rituals specific to each society in each epoch, whose cultivation serves to stabilize and convey that society's self-image" [59]. Cultural memory appeared to be important for all of the users (mobile or static), which opposes Maria Lewicka's (2008) finding that people inhabiting a neighbourhood (static users) will be more interested, concerned, and attached to the place's past [25]. All mobile and static users considered the lost theatre a memorable element, and its presence helped to maintain the same site experience every time they use the place. Now, the removal of this element has resulted in feelings of loss and anger.

The participants' comments show that cultural and personal memories play a role in creating place attachment. As all the participants were attached to the site and the demolished theatre, some participants mentioned living in the area or passing by it every day (behaviour/practice), while others used to use it as a landmark to locate themselves within the city (cognitive), and some remember their memories that recall different feelings (emotions/affective). Participant comments covered three different constructs of place attachment: affective, cognitive, and practice, supporting the place attachment definition by Brown and Perkins (1992): 'Place attachments typically involve positively experienced bonds that individuals and groups form with socio-physical environments, which grow from behavioural, cognitive, and affective ties' [60]. In addition, the participants mentioned their feelings of anger and loss due to the new planning for the site-evidence of their attachment to the old site elements. These emotions were reinforced by Brown, Altman, and Werner's argument that 'humans are so embedded in their environments that they don't always reflect on those bonds unless called to do by outside threats, new situations or turning points in life' [61].

The results also show that place attachment contributes to the formation of place identity through experiencing feelings of continuity and distinctiveness of the site features. The theatre, with its unique form, was significant and marked the area, creating a sense of certainty about knowing and belonging to the place. This idea of place identification is supported by Lynch's explanation that if the physical form and the function of the city scape are clear and identifiable, it will enable people to form clear and accurate images of their places. This will also help them to orient themselves through parks, edges, districts, nodes, and landmarks [62]. However, the results also show that the younger generation enjoys the new site setting and lack that attachment to or feeling for the uniqueness of the old site setting, as opposed to the older generation. This aspect agrees with Siew-William's explanation that transformations in the urban body of the city remove the context of the formation of events and memories. So, familiar landscapes change or degrade quickly, leaving the young generations who live in these cities with no collective memories of or attachment to their surroundings and a concomitant lack of identity [38].

The findings of this study indicate how cultural memory, place attachment, and place identity contribute to a sense of place, agreeing with the argument by Jennifer E. Cross that a sense of place is mainly composed of two aspects: the user's relationship to a place and community attachment [63]. The results show that users experienced different types of bonds to the place, such as biographical, ideological, and narrative bonds. These bonds enhanced their site identification and created the strong emotions of rootedness towards the site. After the changes, they felt that this was not their well-known city's waterfront, and they experienced placelessness. This is aligned with Ralph's (1976) description of 'placelessness'. When places are stripped of their unique attributes, they become common, leading to a compromised place identity [41]. However, placelessness also creates a different type of sense of place, which is the 'nostalgic sense of place', as site users tried to restore their lost sense of place by restoring their past experiences, relations, and stories related to the site-a process reinforced by Eyles' 
1985 definition of a nostalgic sense of place to be 'the product of recalling past sentiments related to place' [64]. These new feelings of placelessness also created a wave of anger in the users and left them insecure, affecting their well-being within the site.

In addition, this result reflects the relation between sense of place with its constructs (place attachment and identity) and well-being. This is in accordance with the view that when attachments to people and places are broken, people experience deep feelings of loss and grief [65]. The result also shows that the stronger the attachment and belonging that people feel towards a favourite site, the more well-being they perceive in that place [66]. This is aligned with the importance of HULs as the storage of tangible and intangible heritage attributes that ensure people's feelings of confidence and connections to their local environments [53]. This is why the participants' comments reflected their feelings of loss and anger towards the ongoing new project. Missing the site's old image, meaning, and stored memories, they consider the new project as lacking any meaning or need within the city's urban fabric. The lack of even a digital record before demolition highlights the lack of consideration for cultural memory in developments of this nature.

In this context, city planners, administrative authorities, and urban planners should consider the importance of cultural memories and their role in creating a sense of place within our HULs to achieve well-being and help people experience a better quality of life.

\section{Conclusions}

This paper began by investigating the importance given to cultural memory by inhabitants of the HUL of the demolished Masrah Al Salam (Al Salam Theatre) in Alexandria, Egypt. Then, it went further to explore the effectiveness of cultural memory in creating a sense of place and well-being and enhancing the quality of life for inhabitants.

This paper revealed how recalling the individual and cultural memories of the site inhabitants was important for their site experience, and how cultural memories as shared memories of the site users contribute to improve psychic health and well-being by reinforcing identity and sense of place through social networks and community attachments. In addition, the research explored the reason behind the city inhabitants' anger about demolishing the theatre and re-planning the whole site through revealing the importance of urban elements such as the Al Salam Theatre in the memorability of the urban environment, which required updating the rules for listing buildings and sites in the heritage lists to honour the intangible dimensions such as cultural memories.

Furthermore, the research explained in detail the effectiveness of cultural memories stored in HULs in creating the different feelings of place attachment and place identity. The results show how recalling the past events, relationships to place, different bonds to place, the site uniqueness, and continuity contributes to the feelings of certainty and rootedness. On the other hand, the results show how the lack of these important relations causes the feelings of placelessness, affecting the site's sense of place and directly affecting people's site experience while invoking the feelings of loss, sadness, and anger. As was clear, from being a unique beautiful building serving as a landmark on the city's waterfront through its form, function, and stored memories, the theatre's site has been reduced to a congested traffic area with a huge new hotel that does not reflect any of the old site's events, memories, or history.

To conclude, it is vital for the government planning agencies to recognise the importance of HULs as storage for cultural memories. It is also important for government agencies to see how the redevelopment and management plans of these sites contribute to the city's image, identity, and sense of place and affect the users' experience, well-being, and quality of life.

Author Contributions: Conceptualization, F.H. and R.T.; Formal analysis, F.H.; Investigation, F.H.; Methodology, F.H.; Resources, J.S. and R.T.; Software, F.H.; Supervision, J.S. and R.T.; Writing-original draft, F.H.; Writing-review \& editing, F.H., J.S. and R.T. All authors have read and agreed to the published version of the manuscript.

Funding: This research received no external funding. 
Acknowledgments: The author acknowledges the support given from Amma Buckley, a Senior Research Fellow at Curtin University, Australia, for her guidance and advice while learning and using the NVivo12 qualitative analysis program for completing this study.

Conflicts of Interest: The authors declare no conflict of interest.

Ethics Approval: All subjects gave their informed consent for inclusion before they participated in the study. The study was conducted in accordance with the Declaration of Helsinki, and the protocol was approved by the Human Research Ethics Committee of Curtin University, Australia (HRE2018-0698).

\section{References}

1. Carrà, N. Identity and Urban Values for Sustainable Design. Adv. Eng. Forum 2014, 11, 470-475. [CrossRef]

2. Leila Mahmoudi, F.; Marzieh, S.; Leila, S. Contextualizing Palimpsest Of Collective Memory In An Urban Heritage Site: Case Study of Chahar Bagh, Shiraz-Iran. Archnet IJAR 2015, 9, 218-231.

3. Molavi, M.; Rafizadeh Malekshah, E.; Rafizadeh Malekshah, E. Is collective memory impressed by urban elements? Manag. Res. Pract. 2017, 9, 14-27.

4. Bandarin, F.; van Oers, R. Reconnecting the City: The Historic Urban Landscape Approach and the Future of Urban Heritage; Bandarin, F., van Oers, R., Eds.; Wiley Blackwell: Chichester, UK, 2015.

5. Ginzarly, M.; Pereira Roders, A.; Teller, J. Mapping historic urban landscape values through social media. J. Cult. Herit. 2019, 36, 1-11. [CrossRef]

6. Taylor, K. Landscape and Memory: Cultural Landscapes, Intangible Values and Some Thoughts on Asia. In Proceedings of the 16th ICOMOS General Assembly and International Symposium: Finding the Spirit of Place-Between the Tangible and the Intangible, Quebec, QC, Canada, 29 September-4 October 2008.

7. Lib, T.M. Memory the Macquarie Library. Available online: https://www.macquariedictionary.com.au/ (accessed on 10 June 2020).

8. Ardakani, M.K.; Oloonabadi, S.S.A. Collective memory as an efficient agent in sustainable urban conservation. Procedia Eng. 2011, 21, 985-988. [CrossRef]

9. Darian-Smith, K.; Hamilton, P. Memory and History in Twentieth-Century Australia; Darian-Smith, K., Hamilton, P., Eds.; Oxford University Press: Melbourne, Australia, 1994.

10. Halbwachs, M. On Collective Memory; Coser, L.A., Ed.; University of Chicago Press: Chicago, IL, USA, 1992.

11. Nora, P. Between Memory and History: Les Lieux de Memoire. In Memory and Counter-Memory; No. 26 Special issue; University of Chicago Press: Chicago, IL, USA, 1989; pp. 7-24.

12. Fine, G. Collective Memory; AGE Publications Inc.: Thousand Oaks, CA, USA, 2005. [CrossRef]

13. Lak, A.; Hakimian, P. Collective memory and urban regeneration in urban spaces: Reproducing memories in Baharestan Square, city of Tehran, Iran. City Cult. Soc. 2019, 18, 100290. [CrossRef]

14. Hałas, E. Issues of Social Memory and their Challenges in the Global Age. Time Soc. 2008, 17, $103-118$. [CrossRef]

15. AlGhanim, K.; Gardner, A.; El-Menshawy, S. The relation between spaces and cultural change: Supermalls and cultural change in qatari society. Sci. Cult. 2017, 3, 21-32.

16. Li, N. Preserving Urban Landscapes as Public History: The Chinese Context. Public Hist. 2010, 32, 51-61. [CrossRef]

17. Jahanbakhsh, H.; Koumleh, M.H.; Alambaz, F.S. Methods and Techniques in Using Collective Memory in Urban Design: Achieving Social Sustainability in Urban Environments. Cumhur. Univ. Fac. Sci. J. (CSJ) 2015, $36,13$.

18. Hidalgo, M.; Hernandez, B. Place attachment: Conceptual and empirical questions. J. Environ. Psychol. 2001, 21, 273-281. [CrossRef]

19. Giuliani, M.V. Theory of attachment and place attachment. In Psychological Theories for Environmental Issues; Bonnes, M., Lee, T., Eds.; Routledge: London, UK, 2003; pp. 137-170.

20. Proshansky, H.M.; Fabian, A.K.; Kaminoff, R. Place-identity: Physical world socialization of the self. J. Environ. Psychol. 1983, 3, 57-83. [CrossRef]

21. Kyle, G.T.; Mowen, A.J.; Tarrant, M. Linking place preferences with place meaning: An examination of the relationship between place motivation and place attachment. J. Environ. Psychol. 2004, 24, 439-454. [CrossRef]

22. Altman, I.; Low, S.M. Place Attachment; Altman, I., Setha, M.L., Eds.; Plenum Press: New York, NY, USA, 1992. 
23. Ujang, N.; Zakariya, K. Place Attachment and the Value of Place in the Life of the Users. Procedia Soc. Behav. Sci. 2015, 168, 373-380. [CrossRef]

24. Williams, D.R.; Patterson, M.E.; Roggenbuck, J.W.; Watson, A.E. Beyond the commodity metaphor: Examining emotional and symbolic attachment to place. Leis. Sci. 1992, 14, 29-46. [CrossRef]

25. Lewicka, M. Place attachment, place identity, and place memory: Restoring the forgotten city past. J. Environ. Psychol. 2008, 28, 209-231. [CrossRef]

26. Jaskiewicz, M. Place attachment, place identity and aesthetic appraisal of urban landscape. Pol. Psychol. Bull. 2015, 46, 573-578. [CrossRef]

27. Montgomery, J. Making a city: Urbanity, vitality and urban design. J. Urban Des. 1998, 3, 93-116. [CrossRef]

28. Ujang, N. Place Attachment and Continuity of Urban Place Identity. Procedia Soc. Behav. Sci. 2012, 49, $156-167$. [CrossRef]

29. Bevan, R. The Destruction of Memory: Architecture at War, 2nd ed.; Bevan, R., Ed.; Reaktion Books: London, UK, 2016.

30. Raymond, C.M.; Brown, G.; Weber, D. The measurement of place attachment: Personal, community, and environmental connections. J. Environ. Psychol. 2010, 30, 422-434. [CrossRef]

31. Jorgensen, B.; Stedman, R. Sense of place as an attitude: Lakeshore owners attitudes toward their properties. J. Environ. Psychol. 2001, 21, 233-248. [CrossRef]

32. Relph, E.C. Place and Placelessness. Research in Planning and Design/A Revision of the Author's Thesis; University of Toronto: London, ON, Canada, 1976.

33. Steele, F. The Sense of Place; CBI Pub. Co.: Boston, MA, USA, 1981.

34. Hummon, D.M. Community Attachment: Local Sentiment and Sense of Place. In Place Attachment; Iaasm, L., Ed.; Plenum Press: New York, NY, USA, 1992.

35. Eisenhauer, B.; Krannich, R.; Blahna, D. Attachments to Special Places on Public Lands: An Analysis of Activities, Reason for Attachments, and Community Connections. Soc. Nat. Resour. 2000, 13, 421-441.

36. Shamai, S.; Ilatov, Z. Measuring sense of place: Methodological aspects. Tijdschr. Econ. Soc. Geogr. 2005, 96, 467-476. [CrossRef]

37. Mohammad, N.M.N.; Saruwono, M.; Said, S.Y.; Hariri, W.A.H.W. A Sense of Place within the Landscape in Cultural Settings. Procedia Soc. Behav. Sci. 2013, 105, 506-512. [CrossRef]

38. Lim, W.S.-W. Memories and urban places. Analysis of urban trends, culture, theory, policy, action. City 2000, 4, 270-277. [CrossRef]

39. WHO. Whoqol: Measuring Quality of Life. In World Health Organization Division of Mental Health and Prevention of Substance Abuse; World Health Organization: Geneva, Switzerland, 1997.

40. Golledge, R.G. Spatial Behavior: A Geographic Perspective; Stimson, R.J., Ed.; Guilford Press: New York, NY, USA, 1997.

41. DeMiglio, L.; Williams, A. A Sense of Place, A Sense of Well-being. In Sense of Place, Health, and Quality of Life; John Eyles, A.W., Ed.; Ashgate: Burlington, VT, USA, 2008.

42. Othman, S.; Nishimura, Y.; Kubota, A. Memory Association in Place Making: A review. Procedia Soc. Behav. Sci. 2013, 85, 54-63. [CrossRef]

43. Hussein, F.; Stephens, J.; Tiwari, R. Cultural Memory For Psychosocial Well-Being In Historic Urban Landscapes An Existing But A Neglected Dimension. Int. J. Soc. Sci. Interdiscip. Stud. (IJSSIS) 2019, 4, 53-59.

44. Hussein, F.; Stephens, J.; Tiwari, R. Cultural Memories for Better Place Experience: The Case of Orabi Square in Alexandria, Egypt. Urban Sci. 2020, 4, 7. [CrossRef]

45. Alexandria Portal Egypt 2019. Available online: http://www.alexandria.gov.eg/Alex/english/index.aspx (accessed on 8 June 2020).

46. JustMaps. Maps of Alexanderia Valencia (Spain): Internet Studios. 2005. Available online: http://www. justmaps.org/maps/images/egypt/alexandria-map2.jpg (accessed on 12 June 2020).

47. Morgan, A. Six Touristic Buildings were Demolished from Alexandria by the End of 2016 (Arabic Source) Sout Al Umma: Sout Al Umma Journal. 2016. Available online: https://www.soutalomma.com/465080 (accessed on 14 June 2020).

48. Deyaa, N. Another Legacy Wasted: Alexandria's Al-Salam Theatre is Demolished. Daily News Egypt. 2016. Available online: https://dailynewsegypt.com/2016/06/26/another-legacy-wasted-alexandrias-al-salamtheatre-demolished/ (accessed on 1 July 2020). 
49. Zeinobia. Farewell El-Salam Theatre of Alexandria “Updated” 2016. Available online: https: //egyptianchronicles.blogspot.com/2016/06/june-13-2016-at-1225am.html (accessed on 15 May 2020).

50. ECO Group. Mostafa Kamel Hotel-Cornish Road-Alexandria Egypt 2020. Available online: http: //ecoalx.com/project/mostafa-kamel-hotel-cornish-road-alexandria/ (accessed on 20 June 2020).

51. Morse, J.M. Designing Funded Qualitative Research. In Handbook of Qualitative Research, 2nd ed.; Denzin, N.K., Lincoln, Y.S., Eds.; Sage Publications Ltd.: Thousand Oaks, CA, USA, 1994; pp. 220-235.

52. Gregory, J. Connecting with the past through social media: The 'Beautiful buildings and cool places Perth has lost' Facebook group. Int. J. Herit. Stud. 2015, 21, 22-45. [CrossRef]

53. van der Hoeven, A. Historic urban landscapes on social media: The contributions of online narrative practices to urban heritage conservation. City Cult. Soc. 2019, 17, 61-68. [CrossRef]

54. Wilson, K.; Desha, C. Engaging in design activism and communicating cultural significance through contemporary heritage storytelling: A case study in Brisbane, Australia. J. Cult. Herit. Manag. Sustain. Dev. 2016, 6, 271-286. [CrossRef]

55. Olsen, W. Triangulation in Social Research: Qualitative and Quantitative Methods Can Really Be Mixed. In Developments in Sociology; Holborn, M., Ed.; Causeway Press: Ormiskirk, UK, 2004.

56. Krippendorff, K. Content Analysis: An Introduction to Its Methodology, 2nd ed.; Sage: Thousand Oaks, CA, USA, 2004.

57. Mapio Net. Available online: https://cdn-0.mapio.net/images-p/23459695.jpg (accessed on 25 May 2020).

58. Ezzeldin, A. "You Won't Believe Who is the Real Sound behind Boa Loz" Translated from Arabic Title Egypt: La2tat.com. Available online: https://www.12tat.com/\%D8\%A3\%D8\%AE\%D8\%A8\%D8\%A7\%D8\% B1-\%D8\%A7\%D9\%84\%D9\%81\%D9\%86\%D8\%A7\%D9\%86\%D9\%8A\%D9\%86/\%D9\%84\%D9\%86-\%D9\% 8A\%D8\%B9\%D8\%B1\%D9\%81\%D9\%87-\%D8\%B3\%D9\%88\%D9\%89-\%D8\%AC\%D9\%8A\%D9\%84-\%D8\% A7\%D9\%84\%D8\%AB\%D9\%85\%D8\%A7\%D9\%86\%D9\%8A\%D9\%86\%D8\%A7\%D8\%AA-\%D9\%84\%D9\% 86-\%D8\%AA \%D8\%B5\%D8\%AF\%D9\%82-\%D9\%85\%D9\%86/.2018 (accessed on 26 June 2020).

59. Kansteiner, W. Finding Meaning in Memory: A Methodological Critique of Collective Memory Studies. Hist. Theory 2002, 41, 179-197. [CrossRef]

60. Brown, B.; Perkins, D. Distruptions in Place Attachment. In Place Attachment; Altman, I., Low, S., Eds.; Plenum: New York, NY, USA, 1992; pp. 279-304.

61. Brown, B.B.; Altman, I.; Werner, C.M. Place Attachment. In International Encyclopedia of Housing and Home; Elsevier: Amsterdam, The Netherlands, 2012; pp. 183-188.

62. Lynch, K. The Image of the City; MIT Press: Cambridge, MA, USA, 1960.

63. Cross, J.E. What is Sense of Place? In Proceedings of the 12th Headwaters Conference, Gunnison, CO, USA, 2-4 November 2001.

64. Eyles, J. Senses of Place; Silverbrook Press: Warrington, DC, USA, 1985.

65. Lucy, W. If Planning Includes Too Much, Maybe It Should Include More. J. Am. Plan. Assoc. 1994, 60, 305-318. [CrossRef]

66. Knez, I.; Eliasson, I. Relationships between Personal and Collective Place Identity and Well-Being in Mountain Communities. Front. Psychol. 2017, 8, 79. [CrossRef] [PubMed]

(C) 2020 by the authors. Licensee MDPI, Basel, Switzerland. This article is an open access article distributed under the terms and conditions of the Creative Commons Attribution (CC BY) license (http://creativecommons.org/licenses/by/4.0/). 